\title{
Peranan Desain Kemasan dan Branding Dalam Peningkatan Citra Merek Produk Usaha Unggulan Bandung Selatan
}

\author{
Bob Foster ${ }^{1}$, Fitriani Reyta ${ }^{2}$, Muhamad Deni Johansyah ${ }^{3}$, \\ Bernadetha Nadeak ${ }^{4}$, Elferida Sormin ${ }^{5}$ \\ 1,2Universitas Informatika dan Bisnis Bandung, \\ ${ }^{3}$ Universitas Padjajaran, ${ }^{4,5}$ Universitas Kristen Indonesia \\ E-mail : bobriset@unibi.ac.id ${ }^{1}$, fitrianireyta@unibi.ac.id ${ }^{2}$, muhamad.deni@unpad.ac.id ${ }^{3}$, \\ bernadetha.nadeak@uki.ac.id ${ }^{4}$, elferida.sormin@uki.ac.id ${ }^{5}$.
}

\begin{abstract}
Abstrak
Keunikan kemasan dan bahan kemasa yang berkualitas seringkali menjadikan produk tertentu dinilai memiliki citra merek yang baik di benak konsumen, sebaliknya produk yang di kemas seadanya dan bahan kemasan yang berkualitas rendah menjadikan suatu produk dinilai memiliki citra merek yang rendah. White tea merupakan salah satu produk unggulan yang diproduksi oleh usaha mikro di Bandung selatan tepatnya desa Gambung, Pangalengan. Perkebunan teh Gambung berada di Desa Cisondari, Kecamatan Pasir Jambu, Pangalengan, Kabupaten Bandung menjadi salah satu daerah dengan komoditas teh terbaik di Indonesia, bahkan sampai ke pasar mancanegara yaitu ke pasar komoditas teh di Inggris dan Amsterdam, dirintis oleh Rudolph Eduard Kerkhoven, warga Belanda pada abad 18. Kepemilikan perkebunan teh beragam di Gambung, milik pemerintah, swasta dan masyarakat lokal. Salah satu usaha yang berkembang dikarenakan permintaan tinggi adalah produk white tea.

Kemasan produk teh asal Gambung masih dirata ratakan sederhana dan berbahan dasar dus atau kertas dan branding sederhana sehingga produk mahal menjadi terkesan murah, dan menurunkan citra merek juga permintaan produk. Penelitian ini merupakan hasil pengabdian masyarakat yang dilakukan oleh akademisi Universitas Informatika dan Bisnis Indonesia bekerja sama dengan Universitas Padjajaran Bandung, tujuan penelitian adalah untuk mengetahui faktor kemasan dan branding sebagai pendorong penningkatan citra yang dibentuk oleh kemasan dan branding tersebut, 100 responden diambil secara acak dari bagian populasi konsumen loyal di café di kota Bandung. Hasil pengolahan kuisioner menggunakan partial least square menyatakan ada pengaruh desain dan bahan kemasan juga branding terhadap citra merek produk teh putih yang diproduksi oleh usaha Menengah asal Gambung, Kab Bandung, Jabar.
\end{abstract}

Kata Kunci : Desain kemasan, Branding, White tea, Pangalengan, Usaha Unggulan.

\begin{abstract}
The uniqueness of packaging and quality packaging materials often make certain products considered to have a good brand image in the minds of consumers, on the other hand, products that are improperly packaged and packaging materials of low quality make a product considered to have a low brand image. White tea is one of the superior products produced by micro businesses in southern Bandung, to be precise, Gambung village, Pangalengan. Gambung tea plantation located in Cisondari Village, Pasir Jambu District, Pangalengan, Bandung Regency is one of the areas with the best tea commodities in Indonesia, even to foreign markets, namely the tea commodity market in England and Amsterdam, initiated by Rudolph Eduard Kerkhoven, a Dutch citizen. in the 18th century. Ownership of various tea plantations in Gambung, belonged to government, private and local communities. One of the businesses that is growing due to high demand is white tea products.
\end{abstract}

The tea product packaging from Gambung is still averaged simple and made from boxes or paper and simple branding so that expensive products seem cheap, and reduce the brand image as well as product demand. This research is the result of community service 
carried out by academics at the University of Informatics and Business Indonesia in collaboration with the University of Padjajaran Bandung, the purpose of this research is to determine the packaging and branding factors as a driving force for enhancing the image formed by the packaging and branding, 100 respondents were taken randomly from the loyal consumer population in cafes in the city of Bandung. The results of processing the questionnaire using partial least squares stated that there was an effect of design and packaging materials as well as branding on the brand image of white tea products produced by medium businesses from Gambung, Bandung Regency, West Java.

Keywords: Packaging design, Branding, White tea, Pangalengan, Leading Business.

\section{PENDAHULUAN}

Sudaryatmo (2011) menyatakan pemahaman merek lokal belum sepenuhnya dapat dipahami dengan jelas di Indonesia. Terdapat empat referensi sebagai kategori merek lokal atau bukan. Pertama, bahan baku berasal dari produk lokal; kemudian diproduksi / diolah di dalam negeri; kemudian menggunakan merek lokal; terakhir diproduksi oleh perusahaan yang sahamnya dimiliki oleh investor lokal. Desa Gambung sejak tahun 2015 sudah mengenal proses produksi white tea dan telah memasarkan produk tersebut baik secara lokal maupun mancanegara.

Bentuk kemasan menggambarkan ukuran produk yang dikemas di dalamnya. Bentuk sebagai persepsi konsumen dalam menentukan isi atau ukuran bobot produk di dalamnya. Beberapa kemasan yang biasanya berukuran lebih besar terdapat pada dry food, kemasan dibuat agar persepsi calon pembeli lebih menarik untuk membandingkan produk pesaing. Bentuk kemasan sangat berpengaruh terhadap potensi psikologis konsumen, dengan bentuk kemasan yang menarik kesan yang baik akan membuat konsumen semakin tertarik untuk membeli. Hal ini banyak diterapkan pada waktu-waktu tertentu biasanya pada hari libur dan libur akhir tahun. Produk biasa terlihat lebih bagus dan menarik jika dikemas secara bundle sehingga terkesan lebih hemat. Bersama dengan bentuk dan tampilan yang unik akan membuatnya lebih menarik bagi konsumen. Dari hasil observasi yang dilakukan sebelumnya, terdapat permasalahan utama dari produk lokal white tea yaitu rendahnya citra merek dan kepercayaan terhadap tampilan produk usaha menengah produk, berbeda dengan produk yang lebih baik 
Volume 2, Nomor 2, Tahun 2020 Hal 479 - 485

kemasan nya asal produsen yang lebih maju dan memiliki teknologi pengamasan lebih baik. Salah satu kemasan produk white tea asal Gambung yang dikemas dengan bahan berkualitas dan desain menarik dapat dilihat pada gambar 1 dan gambar 2 .

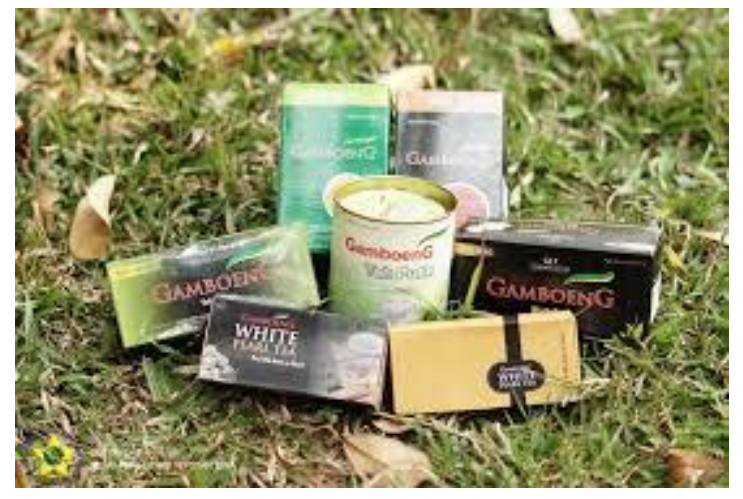

Gambar 1 : White tea Produksi Pusat Penelitian Teh dan Kina Gambung, Kab Bandung, Jawa Barat.

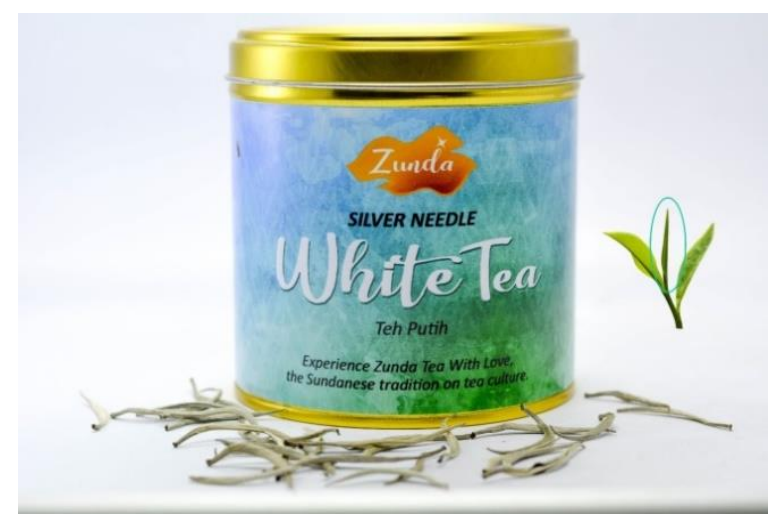

Gambar 2 : White tea produksi Zunda Indonesia.

Desain kemasan dan permainan warna pada kedua produk white tea diatas telah terbukti mempengaruhi minat beli konsumen, Foster dkk (2019) menyatakan keunikan kemasan terbukti meningakatkan pengaruh brand awareness dan pemberdayaan produk terhadap mempengaruhi minat beli konsumen merek teh putih di Bandung, Jawa Barat, Indonesia. Maslakhah dan Sutopo (2017) menyatakan desain kemasan juga mempengaruhi citra merek produk dan memiliki dampak positif pada keputusan pembelian konsumen. Sial, dkk (2011) bahwa terdapat pengaruh positif antara kemasan dengan citra merek, semakin menarik desain kemasan maka citra merek akan semakin meningkat.

Desain dan warna pada kemasan mempengaruhi penyampaian pesan secara kognitif terhadap calon pembeli, Aaker (1997) menyimpulkan bahwa terdapat lima warna yang mendominasi pasar dengan masing-masing catatan kognitif, yaitu biru muda melambangkan ketulusan, merah melambangkan minat, hijau melambangkan kompetensi, ungu melambangkan kemapanan dan kuning melambangkan ketahanan. Warna di atas tidak mutlak dapat dijadikan sebagai dominasi warna dalam desain produk, konsumen dengan latar belakang demografi memiliki selera dan persepsi yang berbeda pula. Studi yang dilakukan oleh Joe Hallock (2003) dalam "color 
assignment" bahwa konsumen baik pria maupun wanita menyukai produk yang didominasi warna biru muda, dan tidak menyukai produk dengan warna coklat. Responden sebagian besar adalah masyarakat Eropa. Dalam kasus yang berbeda, persepsi warna mempengaruhi budaya seperti merah muda adalah warna perempuan. Sedangkan hitam dan biru tua adalah warna jantan. Faktor lain yang menentukan dalam desain produk adalah pemilihan teks atau font serta foto atau gambar yang digunakan. Tujuan pengemasan selain untuk melindungi adalah untuk menjual produk dengan kemasan dan desain yang tepat, untuk mendapatkan perhatian konsumen yang potensial sehingga mengarah pada proses pembelian.

Mufreni (2016) menyatakan dalam industri teh bubuk di Indonesia, sebagian besar produk teh bubuk dijual di pasaran menggunakan kemasan aluminium foil atau tabung kertas dilapisi dengan aluminium foil. Serupa dengan permasalahan produsen teh Usaha Menengah di Gambung, mengemas produknya dengan aluminium foil berwarna silver yang ditempel dengan stiker sederhana tanpa aturan kemasan menarik, tidak termasuk atribut kemasan termasuk barcode, halal, nomor industri produk rumah tangga, bahan, tanggal kadaluwarsa, tanggal produksi, saran pelayanan dan informasi perusahaan membuat keberadaan produk lokal ini sangat rentan terhadap daya saing, apalagi jika tidak memiliki desain kemasan yang menarik yang dapat meningkatkan citra merek, permasalahan tersebut melatarbelakangi penelitian ini.

\section{Kemasan dan Desain Visual Kemasan}

Pengemasan berfungsi sebagai sarana informasi dan pemasaran yang baik, terutama jika didesain dengan kreatif dan menarik sehingga mudah diingat oleh konsumen. Kemasan sebagai kegiatan yang dilakukan oleh perusahaan yang terdiri dari struktur desain, desain grafis, dan informasi produk (Cahyorini dan Rusfian, 2011). Berbeda dengan Cahyorini dan Rusfian, Danger (1992) melihat kemasan sebagai wadah atau pembungkus yang berguna untuk menyiapkan barang agar siap untuk ditransportasikan, didistribusikan, disimpan, dijual, dan digunakan, dengan adanya kemasan, produk di dalamnya akan terlindungi. Klimchuk dan Krasovec (2006) melihat kemasan sebagai desain 
kreatif yang menghubungkan struktur, material, bentuk, warna, dan elemen desan dengan informasi produk lainnya agar dapat dipasarkan,

Sebuah desain kemasan yang baik harus mampu mempengaruhi konsumen untuk memberikan respons positif tanpa disadarinya. Sering terjadi konsumen membeli suatu produk yang tidak lebih baik dari produk lainnya walaupun harganya lebih mahal. Dalam hal ini dapat dipastikan bahwa terdapat daya tarik tertentu yang mempengaruhi konsumen secara psikologis tanpa disadarinya. Desain kemasan menjadi salah satu sarana untuk mengkomunikasikan isi produk secara visual. Sebenarnya mengemas dan kemasan memiliki arti yang berbeda. Mengemas adalah tindakan membungkus atau menutup suatu barang atau sekelompok barang. Sedangkan kemasan mengacu pada objek fisik itu sendiri (Klimchuk and Krasovec). Menurut Nillson \& Armstrom (Cahyorini \& Rusfian, 2011), variabel desain kemasan terdiri dari 3 dimensi yaitu: desain grafis, struktur desain, dan informasi produk.

\section{Branding}

\section{Citra Merek}

Sangadji dan Sopiah (2013) menyatakan bahwa citra merek adalah seperangkat ingatan yang ada dibenak konsumen mengenai sebuah merek, baik itu positif maupun negatif. Citra merek yang positif memberikan manfaat bagi produsen untuk lebih dikenal konsumen, dengan kata lain konsumen akan menentukan pilihannya untuk membeli produk yang mempunyai citra merek yang baik. Dimensi citra merek menurut aker dalam Aris Ananda (2010: p.10) adalah: 1) Recognition (pengakuan) yaitu tingkat dikenalnya sebuah merek oleh konsumen. 2) Reputation (reputasi) tingkat atau status yang cukup tinggi bagi sebuah merek karena lebih terbukti memiliki track record yang baik. 3) Affinity (afinitas) yaitu suatu emosional relationship yang timbul antara sebuah merek dengan konsumennya. Produk dengan merek yang disukai oleh konsumen akan lebih mudah dijual dan produk dengan memiliki persepsi kualitas yang tinggi akan memiliki reputasi yang baik. 4) Domain yaitu seberapa besar scope dari suatu produk yang akan menggunakan 
merek yang bersangkutan. Domain, domain ini mempunyai hubungan yang erat dengan scale of scope.

\section{METODE}

Penelitian ini menggunakan pendekatan kuantitatif eksploratif, pengujian data menggunakan kuisioner dan pengolahan data menggunaakan uji statistik partial least square diolah dengan bantuan software statistik Smart PLS. Penentuan jumlah sampel menggunakan pendekatan Malhotra (2006:291) disebutkan dalam buku riset pemasaran paling sedikit harus empat atau lima kali dari jumlah item pertanyaan. Sehingga dalam penelitian ini menggunakan 120 sampel yang diperoleh dari $5 \times 24$ (jumlah item pertanyaan). Sampel diambil dari populasi konsumen café di Kota Bandung yang loyal mengkonsumsi teh premium.

\section{HASIL DAN PEMBAHASAN}

Pada penelitian ini hasil kuisioner dari 120 sampel responden diuji menggunakan software Smart PLS, gambar 1.4 dibawah ini menggambarkan hasil pengujian dimana desain kemasan dan branding terbukti secara signfikan mempengarungi peningkatan citra merek produk white tea, nilai path coefficient sebesar 0.353 untuk desain kemasan dan 0.443 untuk branding, sedangkan pengaruh secara bersamaan adalah sebesar 0,577 atau 57, $7 \%$ terhadap citra merek.

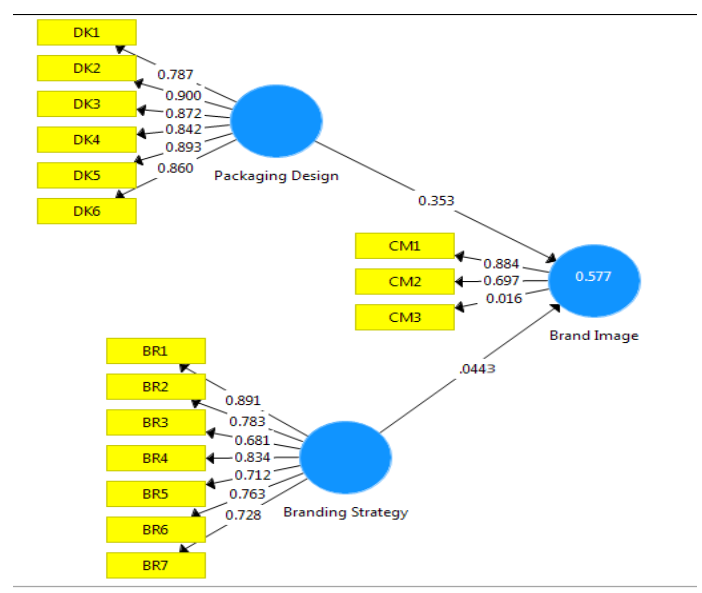

\section{Gambar 1.4 Hasil Penelitian Melalui Pengujian PLS}

Hasil pengujian tersebut mengindikasikan bahwa apabila strategi dilakukan secara parsial mempengaruhi lebih kecil terhadap peningkatan citra merek, sebaliknya jika dilakukan secara simultan akan menghasilkan pengaruh lebih besar, artinya kedua strategi baik desain kemasan dan branding lebih baik dilaksanakan secara komprehensif tidak terpisah. Semakin baik perancangan desain dan branding strategy maka semakin baik pula citra merek di benak konsumen. Dari 120 responden penikmat teh premium di café di kota 
Bandung menyetujui bahwa desain kemasan dan branding strategy adalah faktor penting dalam peningkatan citra merek produk white tea.

\section{SIMPULAN}

Penelitian ini mendukung hasil penelitian dari Kotler dan Pförtsch (2006); Sial, dkk (2011); Joe Hallock; (2003); Aaker (1997). Bahwasanya sebuah desain kemasan yang baik harus mampu mempengaruhi konsumen untuk memberikan respons positif tanpa disadarinya. Sering terjadi konsumen membeli suatu produk yang tidak lebih baik dari produk lainnya walaupun harganya lebih mahal. Dalam hal ini dapat dipastikan bahwa terdapat daya tarik tertentu yang mempengaruhi konsumen secara psikologis tanpa disadarinya adalah pernyataan yang sesuai dengan hasil penelitian ini, dimana semakin menarik desain kemasan akan membuat konsumen secara tidak sadar membentuk citra yang "berkualitas" di benak mereka. Strategi "color assignment" juga terbukti menambah citra merek yang baik di benak konsumen dari sebelumnya hanya sekedar satu tone warna silver. Bahan kemasan juga mempengaruhi citra merek yang berkualitas, semakin dapat diandalkan dan tahan banting, kemasanakan membuat konsumen semakin menetapkan citra merek yang berkualitas.

Strategi merek sebagai merek teh yang premium juga harus ditingkatkan agar citra merek juga akan naik dengan sendirinya, dari merek "kelas bawah" menjadi merek "premium" dengan mengkomunikasikan merek melalui beragam media komunikasi pemasaran, untuk pasar sasaran responden menengah keatas seperti penikmat teh di café komunikasi pemasaran yang tepat dapat melalui sosial media atau membership group, event maupun publisitas. Untuk itu diperlukan penelitian lebih mendalam untuk mengetahui strategi mengkomunikasikan merek yang paling tepat dengan pasar sasaran. Jumlah responden maupun lama penelitian juga perlu diperluas untuk mendapatkan tingkat akurasi yang lebih tinggi. Keterbatasan jarak penelitian dan covid 19 pandemic membuat penelitia terbatas untuk mengujikan kuisioner kepada sampel. 


\section{REFERENSI}

Aaker, J. L. 1997. Dimensions of brand personality. Journal of Marketing Research Vol. 34, No. 3 (Aug., 1997), pp. 347-356. Sage Publications, Inc

Cahyorini \& Rusfian. (2011). The Effect of Packaging Design on Impulsive Buying. Journal of Administrative Science \& Organization, 11-21.

Klimchuk, M. S. \& Krasovec S.A. (2007). Desain Kemasan Perencanaan Merek Produk yang Berhasil Mulai dari Konsep sampai Penjualan (Bob Sabran, Penerjemah). Jakarta: Erlangga.

Kotler, Philip and Pförtsch A. 2006. B2B Branding Dimensions. https://www.researchgate.net/publi cation/226846703.

Hallock, J. 2003. Colour assignment. Washington: New Media Communications 498.

Malhotra, Naresh K., and David F. Birks. 2012. Marketing Research: An Applied. Approach 3 rd. European Edition. Harlow, England: PrenticeHall.

Sangadji, E.M., dan Sopiah. 2013. Prilaku Konsumen: Pendekatan Praktis. Disertai:Himpunan Jurnal Penelitian. Yogyakarta: Penerbit Andi.

Sial, G. (2011). Impact of Labeling and Packaging on Buying Behavior of Young Consumer with Mediating Role of Brand Image. Interdiciplinary Journal of Contemporary Research in Business, 1022- 1029. 